\title{
Abnormal brown and white fat development in transgenic mice overexpressing glycerol 3-phosphate dehydrogenase
}

\author{
Leslie P. Kozak, Ulrike C. Kozak, and George T. Clarke \\ The Jackson Laboratory, Bar Harbor, Maine 04609 USA
}

\begin{abstract}
Mice carrying $\sim 25$ copies of a transgene encoding glycerol 3-phosphate dehydrogenase expressed from 50 to 200 times the level of enzyme produced by a single copy of the normal endogenous gene. The enzyme constituted $>50 \%$ of the cytoplasmic protein in the brown fat of a transgenic mouse. Young transgenic mice (10 days to 8 weeks of age) appeared physically and reproductively normal; however, at the earliest times analyzed, the amount of brown fat of transgenic mice was greater than that of nontransgenic littermate controls. In contrast, the white fat depots, both subcutaneous and peritoneal, were severely reduced in size. Brown fat in transgenic mice also had larger lipid vacuoles and lower levels of Ucp mRNA, but Ucp mRNA levels were elevated in response to cold. Brown fat hypertrophy and reduction of white fat were particularly pronounced in aged transgenic animals. The results suggest that development of brown and white fat is altered by overexpression of glycerol 3-phosphate dehydrogenase.
\end{abstract}

[Key Words: Transgenic mice; glycerol 3-phosphate dehydrogenase; fat development]

Received June 21, 1991; revised version accepted September 24, 1991.

In nonhibernating mammals, the function of brown fat is to produce heat by nonshivering thermogenesis in response to cold, whereas that of white fat is to store excess calories in the form of triglycerides (Smith and Horwitz 1969; Schwartz and Brunzell 1989|. Brown fat differs from white fat with respect to its increased sympathetic innervation, vasculature, and mitochondrial content (Néchad 1986). Qualitatively, brown fat differs from white fat with respect to the presence of a unique protein, the mitochondrial uncoupling protein (UCP) or thermogenin, which enables the tissue to produce heat (Nicholls and Locke 1984). This protein, located in the inner mitochondrial membrane, uncouples respiration from oxidative phosphorylation (Nicholls and Locke 1984). Activation of thermogenesis is initiated centrally from the hypothalamus by the $\beta$-adrenergic signal transduction pathway (Girardier and Seydoux 1986).

The fat in the newborn mammal is almost exclusively brown fat to satisfy the acute requirement for heat that occurs at birth (Néchad 1986). As the animal ages, brown fat tends to disappear to varying degrees, depending on the species, whereas white fat increases concurrently (Cook and Kozak 1982; Nedergaard et al. 1986; Ricquier et al. 1986; Obregon et al. 1989). In addition, in several species both the mass and activity of brown fat can be increased upon exposure to cold (Smith and Horwitz 1969). Accordingly, it would be expected that precursor cells for both white and brown adipocytes are located within the brown fat depots, as tissue culture experiments suggest (Forest et al. 1987; Poissonet et al. 1988; Kopecky et al. 1990; Rehnmark et al. 1990). White fat depots that are considered to be exclusively white fat, such as parametrial and epididymal fat, may also have the capacity to form brown fat (Young et al. 1984). It is not known, however, whether separate precursor cells are committed to development into either white or brown fat or whether the precursor cells are sufficiently plastic to develop into either type of fat cell depending on the hormonal environment.

To investigate the ontogeny and developmental fate of brown and white fat, we have been pursuing an analysis of the mitochondrial uncoupling protein $(U c p)$ gene and the glycerol 3-phosphate dehydrogenase (GPDH) gene (Gdc-1). GPDH is a cytoplasmic enzyme that catalyzes the reduction of dihydroxyacetone phosphate, a glycolytic intermediate, to glycerol 3-phosphate, a precursor for triglyceride and phospholipid synthesis (Kornberg and Pricer 1953). GPDH is expressed ubiquitously, but most abundantly, in brown fat where, like the mitochondrial UCP, it is induced in response to cold exposure (Ratner et al. 1981). To define the limits of the gene structure that are required for tissue-specific expression in vivo, we have generated transgenic mice. Overexpression of the $G d c-1$ transgene has resulted in some unusual changes in fat development that promise to provide in- 
sights into the ontogenetic interrelationship of brown and white fat.

\section{Results}

\section{Transgenic mice}

A transgene was constructed with the complete intron/ exon region of $G d c-1$ and $1.8 \mathrm{~kb}$ of $5^{\prime}-$ and $1 \mathrm{~kb}$ of $3^{\prime}-$ flanking DNA (Ireland et al. 1986; Fig. 1). Three transgenic lines of mice were produced. The transgene was inserted into single chromosomal sites in head-to-tail arrangements with copy numbers of $\sim 20-30$ (Fig. 1). These lines were named $\mathrm{Tg}$ (MMU; Gdc-1) AlKz, Tg (MMU; Gdc-1) $\mathrm{A} 2 \mathrm{Kz}$, and $\mathrm{Tg}$ (MMU; Gdc-1) $\mathrm{A} 3 \mathrm{Kz}$ (Committee for Standardized Nomenclature 1985) but will be abbreviated $\mathrm{A} 1, \mathrm{~A} 2$, and $\mathrm{A} 3$ in the following text.

To evaluate the quantitative expression of the transgene by enzymatic and RNA analyses without interference from expression of the endogenous gene, we transferred the transgene to a genetic background in which the endogenous $G d c-1$ gene was not expressed. This was accomplished by backcross and intercross matings with $\mathrm{BALB} / \mathrm{cHeA}$ mice, a strain that carries a spontaneous null mutation of Gdc-1 (Prochazka et al. 1989). The endogenous active allele in the transgenic mice can be distinguished from the null allele by a restriction enzyme polymorphism (Fig. 1). Analyses were performed on transgenic mice that were homozygous for the $G d c-1$ null allele. Most analyses were restricted to the Al line because of its superior breeding performance. All enzyme assays were performed on animals tested previously by Southern blot analysis for gene copy number.

\section{Expression of the Gdc-1 transgene}

The expression of the $G d c-1$ transgene was evaluated first by Northern blot analysis. Figure 2 illustrates the intensity of hybridization with a $G d c-1$ probe to total RNA isolated from tissues of a Al transgenic and a $\mathrm{BALB} / \mathrm{cBy}$ control mouse at 8 weeks of age. The relative tissue distribution of $G d c-1$ mRNA in transgenic and normal mice is similar as evidenced by the pattern of hybridization signals of transgenic samples in Figure 2A and control samples in Figure 2B. We have demonstrated previously that both $G d c-1$ mRNA and enzyme protein levels vary over two orders of magnitude in different tissues and that the level of enzyme protein correlates positively with the level of its mRNA (Ratner et al. 1981). Accordingly, to establish further that the relative levels of expression of the transgene resembled those of the endogenous gene, GPDH enzyme activity levels were measured in $100,000 \mathrm{~g}$ supernatant extracts from several tissues of the three transgenic lines and normal BALB/ $\mathrm{cBy}$ mice. The highest levels were found in brown fat and the lowest were found in spleen, although enzyme levels in other tissues were intermediate in a manner similar to the nontransgenic control (Table 1). These results corroborate the analyses of RNA levels (Fig. 2) indicating that mechanisms controlling gene expression in normal tissues are acting also on the transgenes. Because all three transgenic lines show similar patterns of RNA and enzyme levels, the transgene expression is not affected significantly by the insertion site.

It is not uncommon for the expression of transgenes to resemble the normal endogenous genes (Stout et al. 1985; Bieberich et al. 1986; Osborn et al. 1987; Aronow

A

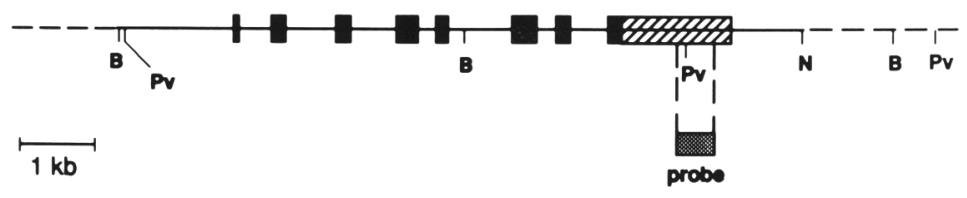

B

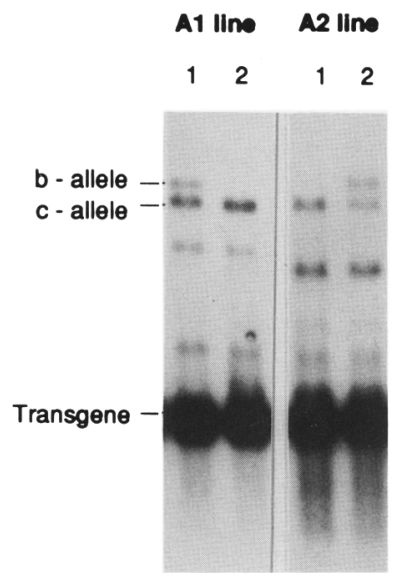

Figure 1. Characterization of $G d c-1$ transgenic mice. (A) A map of the $G d c-1$ gene. Solid boxes represent exon-coding region; the hatched area represents a large untranslated region in the 3' end of the mRNA. The stippled region (probe) is a subcloned DNA fragment from the $3^{\prime}$-untranslated region used as a hybridization probe in the Southern blots illustrated in B. Restriction enzyme sites are BamHI (B), PvuII (Pv), and $\operatorname{Not} \mathrm{I}(\mathrm{N}) .(B)$ Three transgenic lines of mice, $\mathrm{Al}$, $A 2$, and $A 3$, were identified by Southern blot analyses of tail DNA (Brinster et al. 1985) after digestion with $P$ vull. These mice were crossed to BALB/cHeA mice to establish the transgenes on a GPDH-null background. Mice homozygous for the $\mathrm{BALB} / \mathrm{cHeA}$ GPDH-null allele (c-allele) were identified by the presence of the $3.0-\mathrm{kb}$ and absence of the $3.2-\mathrm{kb}$ PvuII fragment (b-allele). Among the A3 line mice, DNA in lane 2 came from a mouse that was nontransgenic and homozygous for the null allele. 
TRANSGENIC

B S L M CB CC K

A

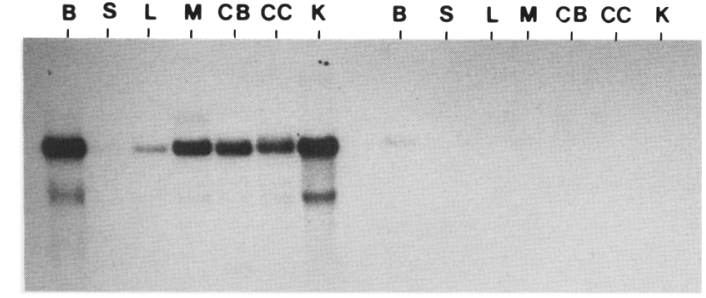

B

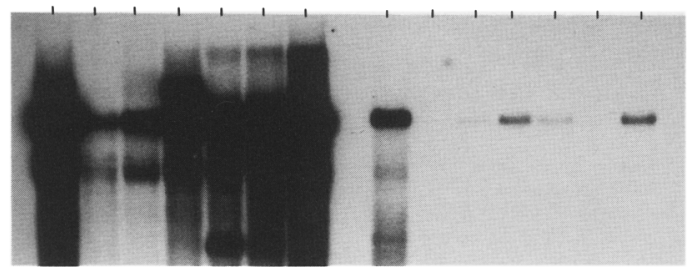

Figure 2. Northern blot analysis of RNA expression in tissues from transgenic mice (line $\mathrm{Al}$ ) and a $\mathrm{BALB} / \mathrm{cBy}$ control mouse. (A) The filters were exposed to film for $4 \mathrm{hr} ;(B) 20 \mathrm{hr}$. The tissues analyzed were brown fat $(B)$, spleen $(S)$, liver $(\mathrm{L})$, skeletal muscle $(M)$, cerebellum $(C B)$, cerebral cortex $(C C)$, and kidney (K). Each lane contained $10 \mu \mathrm{g}$ of total RNA.

et al. 1989); however, it is surprising that the Gdc-1 transgene retains quantitative tissue distributions that resemble the endogenous gene even though the expression of the transgene is so extraordinarily high. A visual impression of the abundance of GPDH in cytosolic extracts from tissues of the Al line is illustrated by the SDS-polyacrylamide gel stained for protein with Coomassie blue (Fig. 3). The GPDH band at $37 \mathrm{kD}$ is dominant in all transgenic tissues except the spleen, whereas the GPDH band is not evident in any of the extracts from the normal mice. Furthermore, the highest specific activity reported in the literature for purified GPDH is $\sim 350 \mathrm{U} / \mathrm{mg}$ of protein (Kozak and Burkart 1981), and we have measured specific activities as high as $268 \mathrm{U} / \mathrm{mg}$ of protein in the crude extracts of brown fat of the Al line. Thus, both SDS-PAGE and enzymatic analyses indicate that GPDH protein exceeds $50 \%$ of the protein of the brown fat cytoplasm. The characteristics of expression in the cerebellum is even more striking, because enzymatic and SDS-PAGE analyses indicated that $\sim 25 \%$ of the cytoplasmic protein is GPDH, yet the complex pattern of high expression in the Bergmann glial cells was indistinguishable from normal tissue (Fig. 4; Fisher et al. 1981). We also found a normal pattern for expression of the transgene in the proximal tubule cells of the kidney and in the Sertoli and Leydig cells of the testis (Fig. 4; Ratner et al. 1981). There are two important conclusions from these studies: (1) The information for tissue-specific expression is contained in the DNA construct used to make the transgenic mice, and (2) regulation of $G d c$-1 occurs almost exclusively at the level of the gene.

\section{Morphological and physiological effects of the Gdc-1 transgene}

The physiological effects of extremely high levels of GPDH in the transgenic mice were not obvious. In the A1 transgenic line, the most thoroughly studied line, litter sizes were normal, the physical appearance and behavior were also normal, and body weight in young animals was similar to nontransgenic controls. However, during the course of removing tissues for biochemical assays, it became evident that the brown fat of transgenic mice was larger than that of the nontransgenic littermate controls (Fig. 5A). Furthermore, the white fat that covers the brown fat as the animal ages failed to appear. Subsequently, we noticed that the transgenic animals were also lacking omental, epididymal, and subcutaneous fat (Fig. 5B). The data in Table 2 are used to compare white fat and brown fat wet weights in transgenic mice and their littermate controls between 1 month and 10 months of age. The interscapular brown fat in the transgenic mice increases in size to $700 \mathrm{mg}$ by 10 months of age. This is approximately four times higher than the weight of brown fat in the nontransgenic controls. Even more striking are the differences in white fat, where it is possible to have just the epididymal fat weighing 3.0 grams in a control mouse, but no detectable fat, including subcutaneous fat, in any region of the

Table 1. GPDH enzyme activities in transgenic lines

\begin{tabular}{lcccc}
\hline & \multicolumn{1}{c}{ Al } & A2 & A3 \\
\cline { 2 - 5 } & \multicolumn{4}{c}{ (U/mg protein) } \\
\hline BAT & $4.5 \pm 1.4$ & $218 \pm 33(48)$ & $76 \pm 27$ & $74 \pm 28$ \\
Liver & $0.34 \pm 0.16$ & $60 \pm 14(176)$ & $21 \pm 8$ & $21 \pm 7$ \\
Kidney & $0.77 \pm 0.28$ & $52 \pm 12(67)$ & $26 \pm 12$ & $17 \pm 2$ \\
WAT & $0.94 \pm 0.28$ & $61 \pm 27(65)$ & $38 \pm 22$ & $35 \pm 16$ \\
Spleen & $0.05 \pm 0.02$ & $15 \pm 4(300)$ & $4.9 \pm 1.1$ & $4.2 \pm 0.3$ \\
Cerebellum & $0.71 \pm 0.40$ & $94 \pm 20(134)$ & $34 \pm 19$ & $34 \pm 5$ \\
\hline
\end{tabular}

Data are presented as the mean \pm S.D. of determinations in five animals for each genotype. Data from males and females at $\sim 7$ weeks of age were pooled. Transgenic mice were heterozygous for the transgene complex and homozygous for the Gdc-1 null allele at the endogenous gene. The control $(+/+)$ mice were the BALB/cByJ inbred strain. Numbers in parentheses refer to the ratio of activity in Al to $+/+$ animals. 


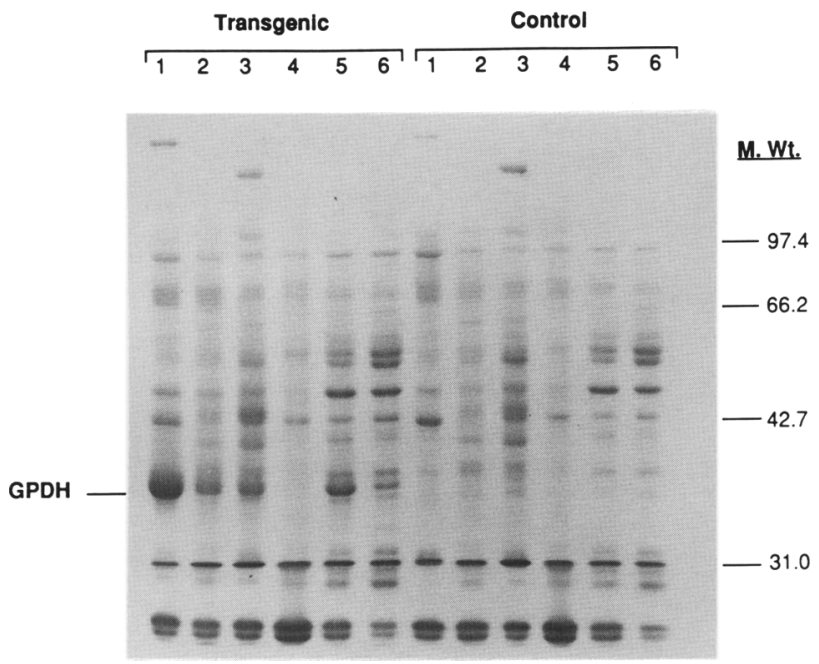

Figure 3. SDS-PAGE of tissue extracts. Brown fat (lane 1), liver (lane 2), kidney (lane 3), spleen (lane 4), cerebellum (lane 5), and cerebral cortex (lane 6) from the Al transgenic and normal $\mathrm{BALB} / \mathrm{cBy}$ mice were homogenized in 5 volumes of $50 \mathrm{~mm}$ Tris (pH 7.5), $1 \mathrm{~mm}$ EDTA, and $1 \mathrm{~mm} \beta$-mercaptoethanol and centrifuged for $1 \mathrm{hr}$ at $100,000 \mathrm{~g}$. After determining GPDH enzyme activity (Kozak and Jensen 1974) and protein concentrations (Bradford 1976), $20 \mu \mathrm{g}$ of protein from each tissue was run on SDS-polyacrylamide gels, as described (Laemmli 1978), and stained with Coomassie blue. Western blot analysis of the brown fat proteins with anti-GPDH antibodies showed intense immunoreactive staining at the expected location /data not shown).

transgenic mouse (Table 2). In some transgenic mice white fat is present in small amounts, and it appears histologically and biochemically normal data not shown). The wet weight of epididymal fat in a transgenic mouse has never exceeded 0.3 gram.

The brown adipocyte is characterized by a dense cytoplasm with multilocular lipid droplets caused by its high content of mitochondria; in contrast, the white fat cell has a single large lipid droplet that occupies most of the cytoplasmic space. Histologically, the interscapular brown fat of a normal mouse shows large areas of typical brown fat cells as well as regions of white fat (Fig. 6A). In contrast, only one type of fat cell is detectable in the brown fat of the transgenic mouse (Fig. 6B). Unlike the normal white adipocyte, and similar to the brown adipocyte, the transgenic cell possesses multiple cytoplasmic lipid droplets; however, these droplets are larger and less numerous than those present in the normal brown adipocyte. The brown fat of the transgenic mice shows a strong similarity to denervated brown fat (Sidman and Fawcett 1954). Denervation also causes an increase in lipid content in a brown fat cell. The detection of only a single type of cell suggests further that the morphological differentiation resulting in the appearance of the white adipocyte has been repressed.

To evaluate whether an increase in cell number also contributed to the greater mass of brown fat in the transgenic mice, the DNA content of brown fat was mea- sured, however, we were unable to detect significant differences in the total DNA content per tissue. This suggests that the increase in brown fat weight is probably the result of cellular hypertrophy due to increased lipid accumulation. It should be noted that the liver also weighed more and showed increases in lipid deposition in older transgenic animals. There was no histologic evidence of lipid accumulation in kidney nor brain. An important implication of these findings is that the balance between white fat and brown fat in the adult, even in the normal adult, may not be fixed and immutable but that the metabolic activity of carbohydrate and lipid metabolism in the brown fat and other tissues during postnatal development may influence the distribution and composition of fat in the normal adult.

\section{Effects on thermogenesis}

We evaluated whether the tissue that we removed from the interscapular region possessed the essential properties of brown fat; namely, that it contained UCP and that $U c p$ expression was induced by exposure to cold. RNA

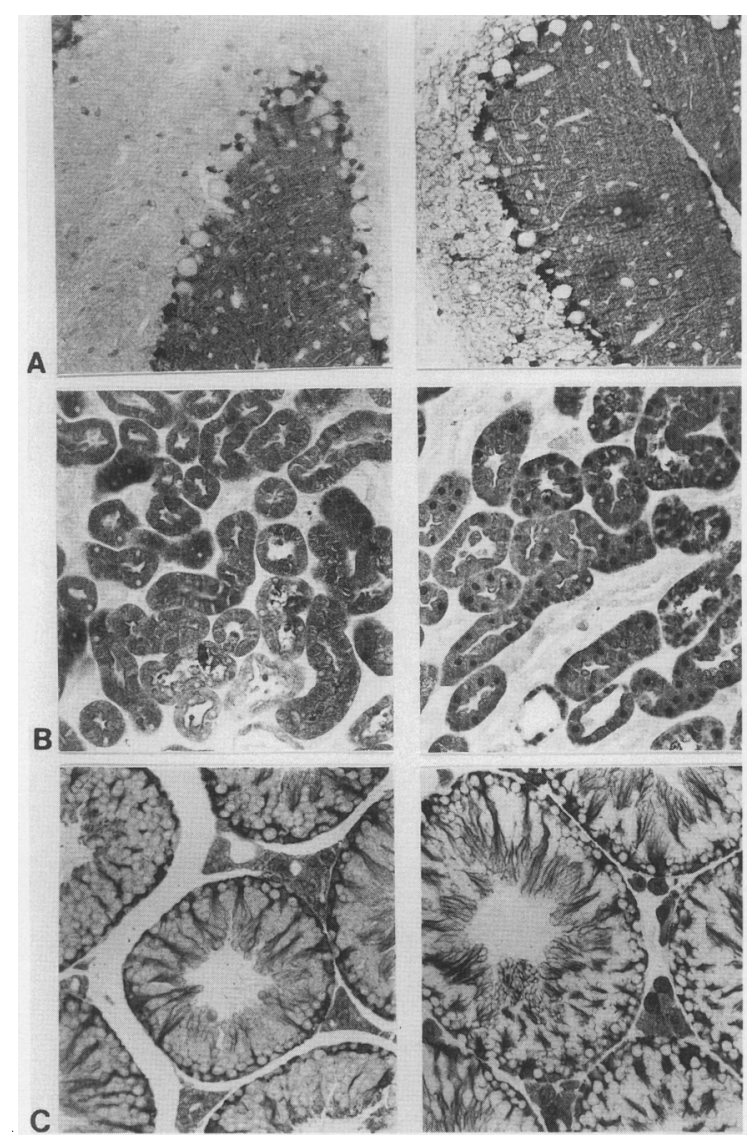

Figure 4. Immunoperoxidase localization of GPDH in cerebel$\operatorname{lum}(A)$, kidney $(B)$, and testis $(C)$ of the $\mathrm{Al}$ transgenic (right) and $\mathrm{BALB} / \mathrm{cBy}$ control (left) mice. Magnification, $400 \times$. (For the staining procedure, see Ratner et al. 1981.) Immunostaining for GPDH was not detected in tissues from Gdc-1-null BALB/cHeA mice (data not shown). 
Kozak et al.

Figure 5. (A) Dorsal view of $\mathrm{Al}$ transgenic mice (right) and littermate controls (left) illustrating the increase in brown fat size in Al transgenic mice. Note also the reduction of subcutaneous fat in $\mathrm{Al}$ transgenic mice. (B) Ventral view shows the reduction in omental and epididymal fat in the peritoneal cavity of Al transgenic mice (right). (Left) Control mice.
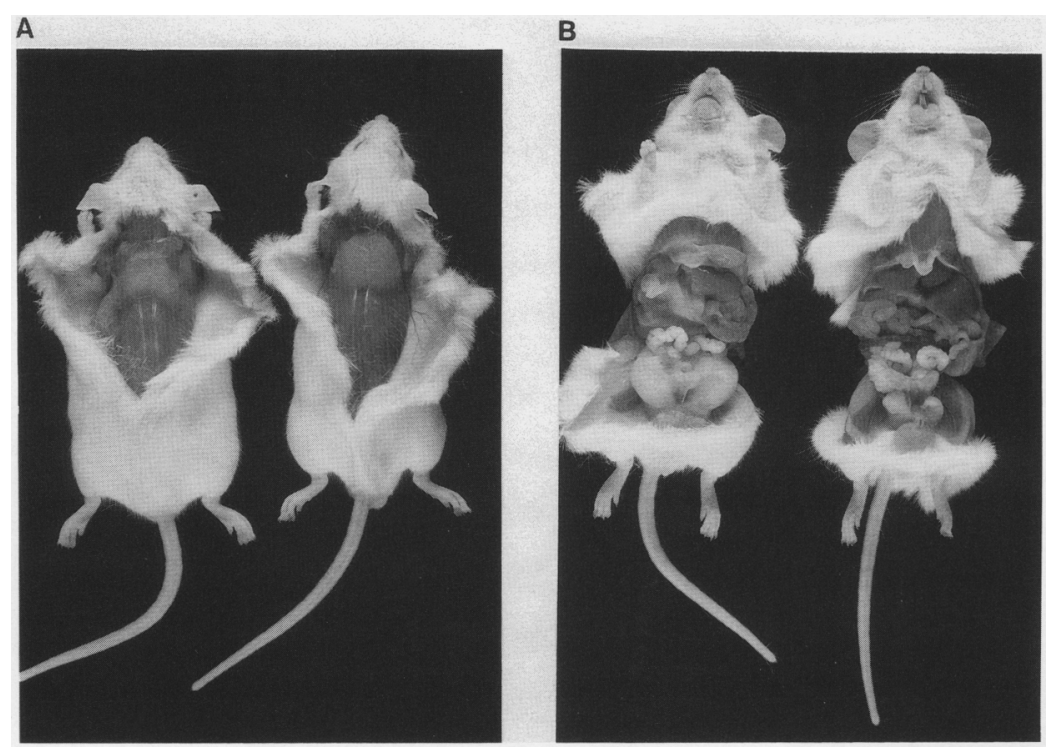

was isolated from 8-week-old transgenic mice and littermate controls maintained at ambient temperature or exposed to $4^{\circ} \mathrm{C}$ for $12 \mathrm{hr}$. RNA was analyzed by Northern blot. The level of $U c p$ mRNA in total RNA preparations from mice maintained at ambient temperature was reduced considerably (Fig. 7, cf. lane 1 with 5-7), suggesting that $U c p$ expression was depressed in transgenic mice. On the other hand, the level of $U c p$ mRNA in both the littermate controls and transgenic mice was elevated to approximately equal levels after exposure to cold (Fig. 7, cf. lanes 2-4 and 8-10), indicating that the interscapular fat from the transgenic animal possessed the essential characteristic of brown fat. Furthermore, the mice showed no difficulty in withstanding the cold. Accordingly, we conclude that the brown fat of transgenic mice functions normally; however, the basis for reduced $U c p$ mRNA levels in mice maintained at ambient tempera- ture is unclear. One possibility is that increased heat production from basal metabolism caused by overexpression of Gdc-1 might reduce the requirement for nonshivering thermogenesis at the ambient temperature of the mouse room. In effect, the thermogenic state of the brown fat would resemble that of an animal at thermoneutrality. This would result in lower UCP levels and also stimulate the accumulation of triglyceride pools in the brown fat. Consistent with this interpretation is the observation that the histology of the transgenic brown fat corresponds to that of denervated brown fat (Sidman and Fawcett 1954).

\section{Discussion}

\section{Overexpression of the transgene}

The data on expression of the Gdc-1 transgene indicates

Table 2. Weights of interscapular brown fat and parietal (female) or epididymal (male) white fat in aging transgenic mice and littermate controls

\begin{tabular}{|c|c|c|c|c|c|}
\hline \multirow{2}{*}{$\begin{array}{l}\text { Transgenic } \\
\text { line }\end{array}$} & \multirow[b]{2}{*}{ Age } & \multicolumn{2}{|c|}{ BAT } & \multicolumn{2}{|c|}{ WAT } \\
\hline & & $\mathrm{Tg} /+$ & $+1+$ & $\mathrm{Tg} /+$ & $+1+$ \\
\hline Al & $10^{\mathrm{a}}$ & $0.076 \pm 0.020(10)$ & $0.044 \pm 0.012(9)^{*}$ & & \\
\hline Al & 1.0 & $0.14 \pm 0.03$ & $0.08 \pm 0.02(7)^{\star}$ & $0.04 \pm 0.02\langle 5\rangle$ & $0.05 \pm 0.03(7)$ \\
\hline Al & 1.5 & $0.20 \pm 0.03$ & $0.13 \pm 0.02\left(\left.3\right|^{\star}\right.$ & not detected $|5|$ & $0.24 \pm 0.10(3)$ \\
\hline A3 & 2.0 & $0.27 \pm 0.03$ & $0.12 \pm 0.04\langle 3\rangle^{*}$ & $0.13 \pm 0.10\langle 3\rangle$ & $0.26 \pm 0.10(3)$ \\
\hline $\mathrm{Al}$ & 5.0 & $0.28 \pm 0.03$ & $0.10 \pm 0.02\langle 3\}^{*}$ & $0.07 \pm 0.08(3)$ & $0.48 \pm 0.26(3)^{*}$ \\
\hline A2 & 5.0 & $0.16 \pm 0.03$ & $0.11 \pm 0.01 \quad\langle 4\}^{\star}$ & $0.18 \pm 0.04\langle 5|$ & $0.30 \pm 0.06(4)^{*}$ \\
\hline $\mathrm{Al}$ & 8.5 & $0.43 \pm 0.17$ & $0.26 \pm 0.13\langle 2\}$ & $0.10 \pm 0.09|3|$ & $3.00 \pm 1.53(2)^{*}$ \\
\hline A3 & 8.5 & $0.40 \pm 0.13$ & $0.09 \pm 0.03\langle 4\}^{*}$ & $0.19 \pm 0.09(4)$ & $1.15 \pm 0.94\langle 4\rangle^{*}$ \\
\hline A1 & 10.5 & $0.58 \pm 0.09|4|$ & $0.14 \pm 0.04\langle 5\rangle^{\star}$ & $0.13 \pm 0.16(4)$ & $2.08 \pm 0.54(5)^{*}$ \\
\hline
\end{tabular}

The data are presented as the mean \pm S.D. of the wet weights in grams. The number of animals of each genotype in a litter is indicated in parentheses.

$\left(^{\star}\right)$ Statistically significant differences between genotypes $(P<0.05)$, determined by Student's $t$ test.

${ }^{a}$ Comparisons at each age (months) were made with transgenic $(\mathrm{Tg} /+)$ and nontransgenic $(+/+)$ animals within a litter except for the 10-day mice, which come from two separate litters. 


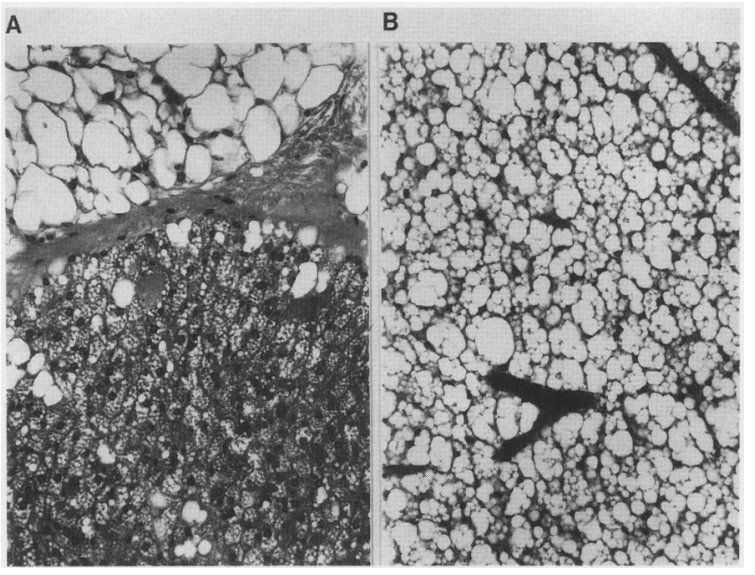

Figure 6. Comparison of the morphology of brown fat from a normal mouse $(A)$ with that from a transgenic mouse $(B)$. Tissues were fixed in Bouin's fixative and embedded in paraffin, and sections were stained with hematoxylin and eosin. Magnification, $150 \times$.

that regulatory elements for tissue-specific expression are contained within the $10 \mathrm{~kb}$ of genomic DNA used to make the transgene. It is unknown where these elements are located. However, we are confronted with the phenomenon that although tissue specificity is retained, Gdc-1 transgene expression greatly exceeded that predicted from the gene copy number and the known activity level of the normal endogenous gene. The most accurate estimates of overexpression of the Gdc-1 transgene are obtained from data for the specific activity of GPDH. Both in vivo (Ratner et al. 1981; Kozak 1985) and in tissue culture (Dani et al. 1986) the level of enzyme has been shown to be directly proportional to the mRNA level. The Northern blot data in Figure 2 also indicate that very high levels of $G d c-1 \mathrm{mRNA}$ are present in these tissues and in the same proportion as observed for the endogenous gene. However, because of the ease of obtaining a higher level of accuracy, to evaluate quantitatively the degree of overexpression, we used measurements of enzyme activity. The increase in the transgenic over the endogenous expression varied inversely in relation to the level of endogenous expression from a low of 48 -fold in brown fat to a high of 300 -fold in spleen. If expression was determined by gene copy number, the increase in transgene expression should not have exceeded 20- to 30-fold. The highest level of overexpression of the transgene was found in spleen, which is also the tissue with the lowest endogenous gene expression. On the other hand, the lowest degree of overexpression (48fold) was observed in brown fat; however, even with this lesser increase in overexpression, GPDH concentration exceeded $60 \%$ of the cytoplasmic protein. It is likely that further increases in expression are not physically compatible with a viable cell. Physical limitations in expression may also be important in the cerebellum and kidney because these tissues have levels of enzyme in their whole-tissue homogenates that correspond to $20 \%$ of to- tal protein, even though the immunohistology indicates that expression is enriched in specific cell types (Fig. 4). Accordingly, cells rich in GPDH, like the glial cells of the cerebellum, may have levels of expression comparable to those of the brown adipocyte.

It has been demonstrated previously that human hemoglobin transgenes carrying only short stretches of flanking sequence show the correct tissue-specific and developmentally dependent expression but are quantitatively underexpressed (Magram et al. 1985; Kollias et al. 1987; Berhinger et al. 1987). Expression of the hemoglobin transgene was normalized by including a dominant positive-regulatory element that is located several kilobases upstream of the normal endogenous gene (Grosveld et al. 1987). By analogy, normal quantitative expression of the $G d c-1$ transgenes might require a negativeregulatory element that is part of the mechanism for regulation of the normal gene, but absent from our transgenic construct. An alternative explanation comes from the novel organizaton of regulatory elements in the transgene complex of 20 copies arranged in head-to-tail orientation (data not shown). We have found recently (J. Jerry, U. Kozak, J. Well, and L. Kozak, in prep.) that a powerful promoter for the $D 15 \mathrm{Kz} 2$ gene is located near the 3' end of the DNA fragment used to make the transgene. $D 15 \mathrm{Kz} 2$ is a transcriptional unit of unknown function located $\sim 1 \mathrm{~kb}$ downstream of Gdc-1 (Kozak et al. 1990). Thus, the start site for each copy of transgenic Gdc-1 has two promoters in the $5^{\prime}$ region that could conceivably augment transcription. This mechanism predicts that significant changes in the size and composition of the Gdc-1 mRNA should have occurred; however, the size of the Gdc-1 mRNA is normal (Fig. 2), and we do not detect larger transcripts originating from the D15Kz2 transcriptional start site (J. Jerry, U. Kozak, J. Well, and L. Kozak, unpubl.). Additional experimentation is required to solve the regulatory basis for overexpression.

\section{A new model system for development of fat}

The qualitative biochemical differences known to exist

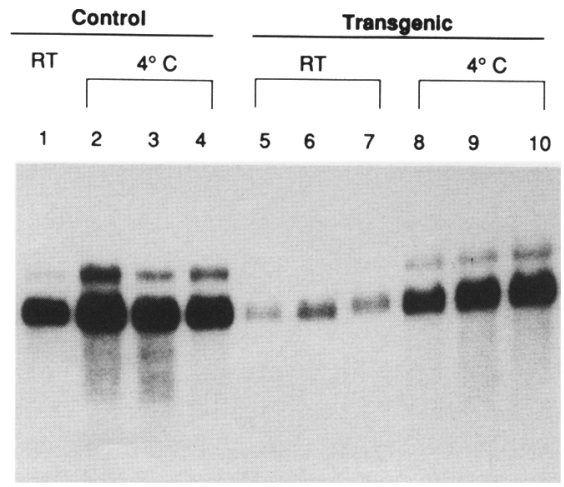

Figure 7. Northern blot illustrating reduced levels of $U c p$ mRNA in the brown fat of Al transgenic mice maintained at room temperature and induction of $U c p$ mRNA when mice are placed in the cold $\left(4^{\circ} \mathrm{C}\right)$. Each lane contained $5 \mu \mathrm{g}$ of total RNA. 
between brown and white fat are minimal. Because fatspecific proteins, including adipocyte $\mathrm{P} 2$ and adipsin, are also expressed in brown fat (Flier et al. 1987; Ross et al. 1990), it is possible that there is no gene restricted specifically to expression in white fat. Conversely, neither UCP nor Ucp mRNA has been detected in white fat. Accordingly, if the expression of $U c p$ is the only qualitative difference between brown and white fat, then the conversion from brown fat to white fat could be accomplished by repression of $U c p$ and modulation of genes that control the high mitochondrial content of the brown fat. That white fat and brown fat are very similar in the location of DNase I hypersensitive sites located in and around $U c p$ indicates that the chromatin structure of $U c p$ in white fat and brown fat are similar (Boyer and Kozak 1991). This suggests that reactivation of $U c p$ is possible in white fat and/or that the two types of fat originate from a common precursor cell.

The overexpression of $G d c-1$ in transgenic mice has provided a model system in which to investigate mechanisms controlling the growth and development of brown and white fat in an animal. Brown fat normally develops before white fat and then involutes (Néchad 1986); however, the presence of the transgene reverses this pattern by stimulating the growth of brown fat and repressing that of white fat. How does overexpression of Gdc-1 alter these growth patterns? Because the role of GPDH in the adipocyte is generally viewed as lipogenic, it is easy to assume that the accumulation of lipid in the brown fat is caused by overexpresssion of Gdc-1. However, the recent analysis of mice carrying the null allele for $G d c$-1 indicates that these mice are not deficient in their body fat content (Prochazka et al. 1989); they are actually inclined toward mild obesity as they mature beyond 1 year of age. For example, the control mouse in Figure 5 was a GPDH null and had a total body weight of 35 grams. Therefore, because the Gdc-1-null mouse is capable of accumulating normal levels of fat, it cannot be assumed that the higher level of fat in the brown adipocyte of the transgenic mouse is the result of increased lipogenesis. On the contrary, the depressed $U c p$ mRNA levels suggest that lipolysis may be decreased in the brown fat, thereby leading to increased lipid accumulation. Accordingly, it is necessary to consider other areas of metabolism to determine the effects of overexpressed, $G d c-1$. The other postulated function for GPDH is to regulate energy metabolism by forming the glycerol phosphate cycle with the mitochondrial GPDH (Bucher and Klingenberg 1958; Estabrook and Sacktor 1958). Lardy and colleagues (1989) have postulated that the use of this pathway can be thermogenic. Whether the stimulation of this pathway by overexpressing $G d c-1$ can account for the reduction of white fat or whether there are alternative pathways of energy inefficiency is currently being investigated. It will also be important to evaluate the effects of the $G d c$-1-null allele and the overexpressing transgenes on the progression of obesity and diabetes in $o b / o b$ and $d b / d b$ mice.

The mechanism controlling the hypertrophy of brown fat in transgenic mice undoubtedly involves those mech- anisms associated with the accumulation of lipid. However, why is the hypertrophy restricted to the brown fat (and in older animals to the liver) and not to white fat in general and, more specifically, to the interscapular white fat that normally accumulates in close association with interscapular brown fat during postnatal development and aging? This problem appears paradoxical given the normal pattern of white fat development. White fat is capable of expanding almost without limit given sufficient levels of calories as observed in obesity, whereas brown fat is repressed, if anything, under these conditions. Relatively small increases in brown fat mass are induced in rodents in response to cold exposure. Primary tissue cultures of cells derived from brown fat precursors transiently express the brown fat phenotype, as evidenced by $U c p$ expression, but inevitably regress to a white fat phenotype on continual culture (Forest et al. 1987; Rehnmark et al. 1990). These data on fat development are consistent with a model in which brown and white fat originate from a common precursor and that conditions during postnatal development favor the outgrowth of white fat from the precursor pool. Thus, there is a powerful movement toward expression of the white fat phenotype, whereas brown fat expression is lost progressively both in vivo and in tissue culture. Given such a strong movement toward the appearance and growth of white fat both in vivo and in vitro, why is this capability not expressed in $G d c-1$ transgenic mice?

In general, the normal pattern of fat development in the nonhibernating mammal involves the involution of brown fat, which is accompanied by the growth of white fat. To understand the involution of brown fat it is necessary to explain the fate of brown fat cells lost during postnatal development. We postulate that apoptosis, or genetically programmed cell death, is a concept important for understanding this phenomenon (Wyllie et al. 1980). Apoptosis has been demonstrated to be an important mechanism of morphogenesis in many species (Saunders 1966). In mammals, it has been studied extensively as the mechanism for the involution of the thymus in response to glucocorticoids (Duvall and Wyllie 1986). Apoptosis, unlike cell necrosis, is a process that requires the activation of specific genes in response to a hormonal or environmental cue. In myeloid leukemic cell lines, it can be induced by introduction of the wildtype p53 tumor-suppressor gene (Yonish-Rouach et al. 1991). Because the involution of brown fat occurs at a precise time in development, it is probable that apoptosis, as well as the expansion of white fat from its precursor pool, is involved in the development of brown fat. In the transgenic mouse, the interscapular brown fat continues to enlarge while the appearance of white fat in the interscapular region never appears. In addition, mesenteric, perirenal, epididymal, and subcutaneous white fat depots in the animal are depressed severely. The changes to the interscapular brown fat, detected by 10 days of age, are the earliest observed effects of overexpression of the transgene. It is possible that the persistence in maintaining the brown fat reflects genetically induced perturbations in realizing the fate of cells in the precursor com- 
partments or death of mature brown fat cells. If overexpression of $G d c-1$ has created a cell that is resistant to apoptosis, it is possible that this transgenic mouse will provide a system for the identification of genes controlling the phenomenon.

\section{Materials and methods}

Construction of Gdc-1 transgenic mice

The 5-kb BamHI fragment at the 5' end of Gdc-1 (Ireland et al. 1986; Fig. 1) was ligated into the BamHI site of Bluescript SK + vector, followed by ligation of the 6-kb BamHI fragment into the SmaI site. Digestion with NotI cuts within the multiple cloning site at the $5^{\prime}$ end of the insert and within the insert $1 \mathrm{~kb}$ from the BamHI site at the $3^{\prime}$ end to release a $10-\mathrm{kb}$ fragment. $G d c-1$ insert and vector DNAs were separated by agarose gel electrophoresis. The $G d c-1$ DNA was recovered by the Geneclean purification procedure according to the manufacturer's instructions. DNA was microinjected into the male pronucleus of $(\mathrm{B} 6 \times \mathrm{LT}) \mathrm{F}_{1}$ zygotes, cultured to the morulae stage, and transferred to pseudopregnant females by The Jackson Laboratory transgenic mouse facility by using methods described previously (Wagner et al. 1981).

\section{Northern blot analysis}

Total RNA was isolated as described by Chomczynski and Sacchi (1987). Northern blots were prepared as described by Derman et al. (1981). Blots were hybridized with a 0.8-kb HindIII fragment containing exon 2 of $G d c-1$ to detect $G d c-1$ mRNA (Ireland et al. 1986) and with a 320-bp BgIII fragment isolated from the Ucp cDNA to detect Ucp mRNA (Kozak et al. 1988). Probes were labeled with $\left[{ }^{32} \mathrm{P}\right] \mathrm{dCTP}$ by the random primer method (Feinberg and Vogelstein 1983).

\section{Acknowledgments}

This research was supported by National Institutes of Health grant HD08431 to L.P.K. We thank Dr. Peter Hoppe of The Jackson Laboratory for production of transgenic mice. We also thank Dr. Joseph Jerry for help with SDS-PAGE, immunohistology, and for useful discussions. The Jackson Laboratory is fully accredited by the American Association of Laboratory Animal Care.

The publication costs of this article were defrayed in part by payment of page charges. This article must therefore be hereby marked "advertisement" in accordance with 18 USC section 1734 solely to indicate this fact.

\section{References}

Aronow, B., D. Lattier, R. Silbiger, M. Dusing, J. Hutton, G. Jones, J. Stock, J. McNeish, S. Potter, D. Witte, and D. Wiginton. 1989. Evidence for a complex regulatory array in the first intron of the human adenosine deaminase gene. Genes \& Dev. 3: 1384-1400.

Berhinger, R.R., R.E. Hammer, R.L. Brinster, R.D. Palmiter, and T.M. Townes. 1987. Two $3^{\prime}$ sequences direct adult erythroid-specific expression of human $\beta$-globin genes in transgenic mice. Proc. Natl. Acad. Sci. 84: 7056-7060.

Bieberich, C., G. Scangos, K. Tanaka, and J. Gilbert. 1986. Regulated expression of a murine class I gene in transgenic mice. Mol. Cell. Biol. 6: 1339-1342.

Boyer, B.B. and L.P. Kozak. 1991. The mitochondrial uncoupling protein gene in brown fat: Correlation between DNase I hypersensitivity and expression in transgenic mice. Mol. Cell. Biol. 11: 4147-4156.

Bradford, M.M. 1976. A rapid and sensitive method for the quantitation of microgram quantities of protein utilizing the principle of protein-dye binding. Anal. Biochem. 72: 248254.

Brinster, R.L., H.Y. Chen, M.E. Trumbauer, M.K. Yagle, and R.D. Palmiter. 1985. Factors affecting the efficiency of introducing foreign DNA into mice by microinjecting eggs. Proc. Natl. Acad. Sci. 82: 4438-4442.

Bucher, T. and M. Klingenberg. 1958. Wege des Wasserstoffs in der lebendigen Organisation. Agnew Chem. 70: 552-570.

Chomczynski, P. and N. Sacchi. 1987. Single-step method of RNA isolation by acid guanidinium thiocyanate-phenolchloroform extraction. Anal. Biochem. 162: 156-159.

Cook, J.R. and L.P. Kozak. 1982. sn-Glycerol-3-phosphate dehydrogenase gene expression during mouse adipocyte development in vivo. Dev. Biol. 92: 440-448.

Dani, C., P. Grimaldi, and G. Ailhaud. 1986. Insulin regulation of glycerol-3-phosphate dehydrogenase gene expression in $\mathrm{Ob} 17$ adipose cells. In Mechanisms of insulin action (ed. P. Belfrage, J. Donnér, and P. Strålfors), pp. 383-394. Elsevier, Amsterdam.

Derman, E., K. Krauter, L. Walling, C. Weinberger, M. Ray, and J.E. Darnell. 1981. Transcriptional control in the production of liver-specific mRNAs. Cell 23: 731-739.

Duvall, E. and A.H. Wyllie. 1986. Death and the cell. Immunol. Today 7: 115-119.

Estabrook, R.W. and B. Sacktor. 1958. Alpha-glycerophosphate oxidase of flight muscle. J. Biol. Chem. 233: 1014-1019.

Feinberg, A.P. and B. Vogelstein. 1983. A technique for radiolabelling DNA restriction endonuclease fragments to high specific activity. Anal. Biochem. 132: 6-13.

Fisher, M., D.A. Gapp, and L.P. Kozak. 1981. Immunohistochemical localization of sn-glycerol-3-phosphate dehydrogenase in Bergmann glial and oligodendroglia in the mouse cerebellum. Dev. Brain Res. 1: 341-354.

Forest, C., A. Doglio, D. Ricquier, and G. Ailhaud. 1987. A preadipocyte clonal line from mouse brown adipose tissue. Exp. Cell Res. 168: 218-232.

Flier, J.S., K.S. Cook, P. Usher, and B.M. Speigelman. 1987. Severely impaired adipsin expression in genetic and acquired obesity. Science 237: 405-408.

Girardier, L. and J. Seydoux. 1986. Neural control of brown adipose tissue. In Brown adipose tissue led. P. Trayhurn and D.G. Nicholls), pp. 123-152. Arnold, London.

Grosveld, F., G.B. van Assendelft, D.R. Greaves, and G. Kollias. 1987. Position-independent, high-level expression of the human $\beta$-globin gene in transgenic mice. Cell 51: 975-985.

Ireland, R.C., M.A. Kotarski, L.A. Johnston, U. Stadler, E. Birkenmeier, and L.P. Kozak. 1986. Primary structure of the mouse glycerol-3-phosphate dehydrogenase gene. I. Biol. Chem. 261: 11779-11785.

Kollias, G., J. Hurst, E. deBoer, and F. Grosveld. 1987. The human $\beta$-globin gene contains a downstream developmental specific enhancer. Nucleic Acids Res. 15: 5739-5747.

Kopecky, J., M. Baudysova, F. Zanotti, D. Janikova, S. Pavelka, and J. Houstek. 1990. Synthesis of mitochondrial uncoupling protein in brown adipocytes differentiated in cell culture. $I$. Biol. Chem. 265: 22204-22209.

Kornberg, A. and W.R. Pricer. 1953. Enzymatic esterification of $\alpha$-glycerophosphate by long chain fatty acids. J. Biol. Chem. 204: 345-357.

Kozak, L.P. 1985. Interactin genes control glycerol-3-phosphate dehydrogenase expression in developing cerebellum of the 
mouse. Genetics 110: 123-143.

Kozak, L.P. and J.T. Jensen. 1974. Genetic and developmental control of multiple forms of $\alpha$-glycerol-3-phosphate dehydrogenase. J. Biol. Chem. 249: 7775-7781.

Kozak, L.P. and D. Burkart. 1981. Immunoisolation and the structural analysis of the sn-glycerol-3-phosphate dehydrogenase isozymes in mouse brain. J. Biol. Chem. 256: 51625169.

Kozak, L.P., J.H. Britton, U.C. Kozak, and J.M. Wells. 1988. The mitochondrial uncoupling protein gene. J. Biol. Chem. 263: 12274-12277.

Kozak, L.P., U.C. Kozak, J. Jerry, and J. Wells. 1990. The glycerol-3-phosphate dehydrogenase gene: Analysis of a complex structural domain and a null mutant. In Obesity: Towards a molecular approach (ed. G. Bray, D. Ricquier, and B. Spiegelman), pp. 263-272. Wiley-Liss, New York.

Laemmli, U.K. 1978. Cleavage of structural proteins during the assembly of the head of bacteriophage T4. Nature 227: 680 685.

Lardy, H., C.-Y. Su, N. Kneer, and S. Wielgus. 1989. Dehydroepiandrosterone induces enzymes that permit thermogenesis and decrease metabolic efficiency. In Hormones, thermogenesis and obesity (ed. H. Lardy and F. Stratman), pp. 415-426. Elsevier, New York.

Magram, J., K. Chada, and F. Constantini. 1985. Developmental regulation of a cloned adult $\beta$-globin gene in transgenic mice. Nature 315: 338-340.

Néchad, M. 1986. Structure and development of brown adipose tissue. In Brown adipose tissue (ed. P. Trayhurn and D.G. Nicholls), pp. 1-30. Arnold, London.

Nedergaard, J., E. Connolly, and B. Cannon. 1986. Brown adipose tissue in the mammalian neonate. In Brown adipose tissue (ed. P. Trayhurn and D.G. Nicholls), pp. 153-213. Arnold, London.

Nicholls, D.G. and R.M. Locke. 1984. Thermogenic mechanisms in brown fat. Physiol. Rev. 64: 1-64.

Obregon, M.J., A. Jacobsson, T. Kirchgessner, M.C. Schotz, B. Cannon, and J. Nedergaard. 1989. Postnatal recruitment of brown adipose tissue is induced by the cold stress experienced by the pups. Biochem. J. 259: 341-346.

Osborn, L., M.P. Rosenberg, S.A. Keller, and M.H. Meisler. 1987. Tissue-specific and insulin-dependent expression of a pancreatic amylase gene in transgenic mice. Mol. Cell. Biol. 7: 326-334.

Poissonet, C.M., M. Ouagued, Y. Aron, J.-Y. Pello, E. Swierczewski, and R. Krishnamoorthy. 1988. Retrieval of precursors for white-type adipose conversion in brown adipose tissue. Biochem. J. 255: 849-854.

Prochazka, M., U.C. Kozak, and L.P. Kozak. 1989. A glycerol3-phosphate dehydrogenase null mutant in BALB/cHeA mice. J. Biol. Chem. 264: 4679-4683.

Ratner, P.L., M. Fisher, D. Burkart, J.R. Cook, and L.P. Kozak. 1981. The role of mRNA levels and cellular localization in controlling sn-glycerol-3-phosphate dehydrogenase expression in tissues of the mouse. J. Biol. Chem. 256: 3576-3579.

Rehnmark, S., M. Néchad, D. Herron, B. Cannon, and J. Nedergaard. 1990. $\alpha$ - and $\beta$-adrenergic induction of the expression of the uncoupling protein thermogenesis in brown adipocytes differentiated in culture. J. Biol. Chem. 265: 16464 16471.

Ricquier, D., F. Bouilland, P. Toumelin, G. Mory, R. Bazin, J. Arch, and L. Pénicaud. 1986. Expression of uncoupling protein mRNA in thermogenic or weakly thermogenic brown adipose tissue. I. Biol. Chem. 261: 13905-13910.

Ross, S.R., R.A. Graves, A. Greenstein, K.A. Platt, H.-L. Shyu, B. Mellovitz, and B.M. Speigelman. 1990. A fat-specific en- hancer is the primary determinant of gene expression for adipocyte P2 in vivo. Proc. Natl. Acad. Sci. 87: 9590-9594.

Saunders, J.W., Jr. 1966. Death in embryonic systems. Science 154: 604-612.

Schwartz, R.S. and J.D. Brunzell. 1989. Energy balance, storage and transport. In Textbook of physiology, vol. 2, pp. 15441561. Saunders, Philadelphia.

Sidman, R.L. and D.W. Fawcett. 1954. The effect of peripheral nerve sections on some metabolic responses of brown adipose tissue in mice. Anat. Rec. 118: 487-507.

Smith, R.E. and B.A. Horwitz. 1969. Brown fat and thermogenesis. Physiol. Rev. 49: 330-425.

Stout, J.T., H.Y. Chen, J. Brennand, C.T. Caskey, and R.L. Brinster. 1985. Expression of human HPRT in the central nervous system of transgenic mice. Nature 317: 250-252.

Wagner, T.E., P.C. Hoppe, J.D. Jollick, D.R. Scholl, R.L. Hodinka, and J.B. Gault. 1981. Microinjection of a rabbit $\beta$-globin gene into zygotes and its subsequent expression in adult mice and their offspring. Proc. Natl. Acad. Sci. 78: 6376-6380.

Wyllie, A.H., J.F.R. Kerr, and A.R. Currie. 1980. Cell death: The significance of apoptosis. Int. Rev. Cytol. 68: 251-306.

Yonish-Rouach, E., D. Resnitzky, J. Lotem, L. Sachs, A. Kimchi, and M. Oren. 1991. Wild-type p53 induces apoptosis of myeloid leukaemic cells that is inhibited by interleukin-6. $\mathrm{Na}$ ture 352: 345-347.

Young, P., J.R.S. Arch, and M. Ashwell. 1984. Brown adipose tissue in the parametrial fat pad of the mouse. FEBS Lett. 167: $10-14$ 


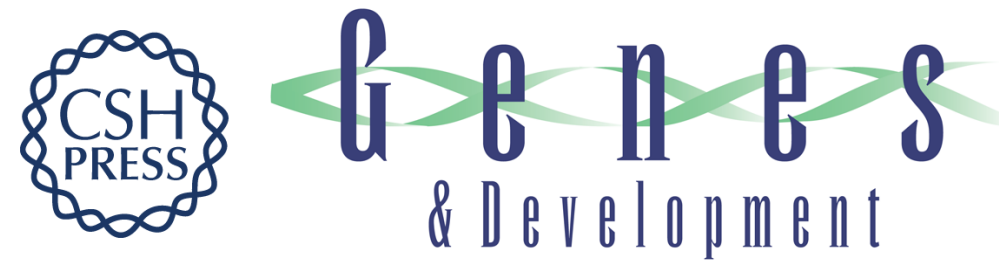

\section{Abnormal brown and white fat development in transgenic mice overexpressing glycerol 3-phosphate dehydrogenase.}

L P Kozak, U C Kozak and G T Clarke

Genes Dev. 1991, 5:

Access the most recent version at doi:10.1101/gad.5.12a.2256

References This article cites 44 articles, 23 of which can be accessed free at:

http://genesdev.cshlp.org/content/5/12a/2256.full.html\#ref-list-1

License

Email Alerting

Service

Receive free email alerts when new articles cite this article - sign up in the box at the top right corner of the article or click here.

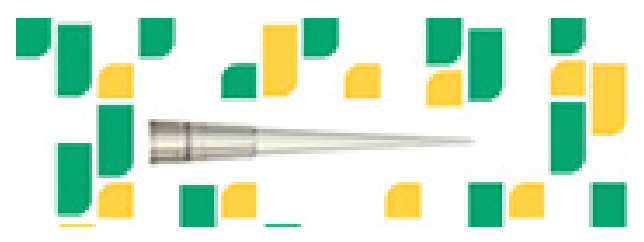

Focused on your science. 